\title{
The Red Road to Wellness: Cultural Reclamation in a Native First Nations Community Treatment Center
}

\author{
Joseph P. Gone
}

Published online: 30 October 2010

(c) Society for Community Research and Action 2010

\begin{abstract}
This article explores how Native American cultural practices were incorporated into the therapeutic activities of a community-controlled substance abuse treatment center on a "First Nations" reserve in the Canadian north. Analysis of open-ended interviews with nineteen staff and clients-as contextualized by participant observation, program records, and existing ethnographic resources-yielded insights concerning local therapeutic practice with outpatients and other community members. Specifically, program staff adopted and promoted a diverse array of both western and Aboriginal approaches that were formally integrated with reference to the Aboriginal symbol of the medicine wheel. Although incorporations of indigenous culture marked Lodge programs as distinctively Aboriginal in character, the subtle but profound influence of western "therapy culture" was centrally evident in healing activities as well. Nuanced explication of these activities illustrated four contributions of cultural analysis for community psychology.
\end{abstract}

Keywords Community psychology - American Indians . Cultural analysis $\cdot$ Medicine wheel $\cdot$ Healing $\cdot$ Substance abuse treatment

The single most significant opportunity for me [in this therapeutic endeavor] is...cultural identity.... We see ourselves as paving the Red Road to wellness.... Paving the Red Road speaks of an attempt to demystify indigenous processes and make it a lot

J. P. Gone $(\bowtie)$

Department of Psychology, University of Michigan, 2239 East

Hall, 530 Church Street, Ann Arbor, MI 48109-1043, USA

e-mail: jgone@umich.edu easier to grapple with this "monster" called identity. Because I believe...that a person who knows who and what they are simply makes healthier lifestyle decisions. So, we need to find ways to allow our people to embrace their own practices. To reclaim. To make the whole process of the cultural renaissance of the Red Man...more palatable to the [Native] on the streets. -Mike, "Healing Lodge" Administrator (2003 Interview)

In the wake of a brutal colonization by European settlers, contemporary Native North American communities are still reeling from the historical legacy of colonial subjugation, coercive assimilation, and imposed poverty. The scale of distress that afflicts many of these communities is frequently overwhelming, both for the resident Native populations and for the surrounding non-Native settler populations who remain ethically and legally obligated to intervene in support of indigenous recovery and well-being. For much of the twentieth century, such interventions remained the purview of a wide range of human services agencies and personnel that bridged the domestic, forensic, educational, medical, religious, and rehabilitative arenas (Polsky 1991). Throughout this period, an overtly psychological frame of reference increasingly transformed these institutions, even while permeating modern society more generally (Ward 2002). Now, in the twenty-first century, the therapeutic sector appears to be flourishing in Native North America (Gone 2004; Kirmayer et al. 2000). Its energies are directed toward the "treatment" of addiction, trauma, violence, suicide, and other "behavioral health" conditions and consequences that continue to disproportionately afflict Native communities (Beals et al. 2005; U. S. Department of Health and Human Services 2001). 
For several decades, however, behavioral health professionals and researchers have observed that "mainstream" psychosocial treatments-offered by mainstream (non-Native) providers-are not well suited for a Native clientele, resulting in failed rapport, botched diagnosis, recalcitrant patients, and ineffective interventions (Devereux 1951; Jilek and Todd 1974; Sue et al. 1978). An oft-cited source of this therapeutic discordance has been "culture." Definitive characterizations of culture and cultural inquiry continue to elude anthropologists (Borofsky et al. 2001), but for the purposes of this article culture may be understood as the socially patterned and historically reproduced systems of semiotic practices that both facilitate and constrain human meaning making (Gone and Kirmayer 2010). In other words, culture refers to shared patterns of activity, interpretation, and interaction that remain both durable and dynamic over time. In this sense, indigenous cultural practices and orientations have been commonly observed to diverge substantially from their "western" counterparts within the therapeutic setting (Brant 1990; Warner 2003). Because psychotherapy and related psychosocial interventions are recognized to express and reproduce these Western sensibilities, indigenous cultural adaptations and alternatives to mainstream approaches have been frequently recommended (Duran 2006; Gone 2010; LaFromboise et al. 1990).

One longstanding recommendation for attaining greater cultural relevance has been to incorporate indigenous therapeutic expertise into service delivery settings by recruiting Native individuals into both formal and informal "helping" roles (Jilek 1971; Torrey 1970). In light of early observations that Native inclusion within these organizations tended to be in lower status paraprofessional positions, some have longed for the day when treatment agencies and programs might fall exclusively under Native administrative authority (Beiser and Attneave 1978; Leon 1968). Nowhere has the realization of this vision of Native administrative control been more extensive than in substance abuse treatment (French 2004). Indeed, in the United States, over eighty percent of substance abuse treatment programs funded by the Indian Health Serviceserving roughly half of the Native treatment populationare administered by tribal governments (McFarland et al. 2006). Native administrative authority over substance abuse treatment services for Native peoples affords a significant degree of autonomy and self-determination relative to issues of cultural accommodation and community responsiveness. Indeed, such programs represent potentially productive sites for investigating the precise ways in which self-conscious discourses about culture are constructed and deployed by formerly colonized peoples engaged in postcolonial re-articulations of self and community.
Surprisingly, however, a formal search of the psychological literature could identify no detailed descriptions of precisely how indigenous cultural practices and processes had been incorporated into specific Native American substance abuse treatment programs and settings. More specifically, three "major descriptor" terms (American Indians, culture [anthropological], and treatment) were entered into the PsycInfo database in July of 2008, returning just three articles and seven chapters. Only one of these provided a concrete instance of cultural incorporation into a Native youth inpatient substance abuse treatment program, in which Boyd-Ball and Dishion (2006) described in three paragraphs how the planning of a "welcome home" ceremony was structured into family week activities. Substitute entry of the term sociocultural factors in place of culture into the PsycInfo database yielded an additional four articles and seven chapters, only one of which described a culturally informed judicial intervention for Native sex offenders (Connors and Oates 1997). In response to so limited a literature, this article undertakes an empirical exploration of the therapeutic activities of an outpatient program within a Native-administered substance abuse treatment center on a "First Nations" reserve in the Canadian north. The purpose of this investigation is to explore how Aboriginal cultural practices were incorporated into the treatment program in order to illustrate how cultural analysis-i.e., the critical engagement of empirically observed phenomena that is oriented by interest in cultural matters-might enhance inquiry within community psychology more generally.

\section{Method}

The research study described in this article was undertaken as one of five empirical case studies commissioned by the Aboriginal Healing Foundation (AHF) in Canada to document the therapeutic activities of a select handful of Native programs funded by the foundation. Briefly, the mission of the AHF is to support sustainable healing processes that redress the colonial legacy of the oppressive residential school system for Canadian Aboriginal people. Substance abuse is seen as just one salient consequence of historically longstanding national efforts to forcibly assimilate Native children through coercive-and frequently barbaric_-educational practices and institutions. Common priorities that guided inquiry across each of the case studies included careful description of the "models" and "metaphors" of healing as these were observed in concept and practice in the designated programs. An overview of the collective research project may be found in Waldram's (2008) introduction to the official AHF report. Additional detail concerning the method for this study can be found elsewhere (Gone 2008, 2009a). 
Setting

The research was conducted in a "Healing Lodge" situated on a northern Algonquian Native (or First Nations) reserve in Canada. The author spent seven weeks on-site between October 2003 and May of 2004 for research purposes. The Lodge is a nationally accredited substance abuse treatment center funded by Health Canada since 1989. At the time of the study, its operating budget approached $\$ 2$ million. The Lodge offered residential, outpatient, and referral services predominantly for an Aboriginal clientele. Although administered independently of the local First Nation, the Lodge was overseen by a board of directors appointed by the reserve government. The Lodge employed roughly two dozen staff members, all of whom were First Nations individuals, and most of whom were citizens of the local tribal community (or "Band"). An interesting feature of the Lodge was its expressed commitment to the integration of Aboriginal cultural traditions with western therapeutic modalities, while simultaneously surpassing the exacting requirements for formal accreditation.

The specific focus of this study was the outpatient "counseling" program. Funded by the AHF since 2000, the program provided therapeutic services to local "survivors" of the residential school system and other residents of the reserve community (totaling some 2,400 Band members). Centered on ameliorating substance abuse-but further extending to a wide range of additional problems identified as the legacy of the residential school experience-the counseling program was staffed by a program coordinator and three counselors, who served up to fifteen clients per 10-week treatment cycle. The program consisted of structured "lectures"-usually accompanied by associated therapeutic activities-for 2-4 h on four evenings per week, as well as one-on-one counseling by appointment as desired. Additional therapeutic activities included coordinated field trips, sponsored cultural events, or participation in ceremonies. Beyond formal client services, community education and outreach activities were a crucial component of the healing mission of the program.

\section{Participants}

Nineteen current and former administrators, counselors, and clients of the program were formally interviewed for this study.

Administrators. The current and former executive directors of the Lodge, the counseling program coordinator, and a member of the counseling program's oversight committee participated in this study. All four of these individuals - three were women, all were middle-agedhad obtained bachelor's degrees, typically in social work. Together they represented decades of combined experience in the human services. Their involvement and familiarity with Lodge programs extended back in some cases to the original establishment of the Lodge in 1989.

Counselors. All four current and former counselors for the program participated in the study, including some who had worked in the counseling program since its inception in 2000. Divided equally by gender, the counselors' ages ranged from early 40 s to mid-60s. Three were themselves residential school survivors, while the fourth had been institutionalized in reform school as an adolescent. All had experienced chaotic lives owing to early family disruption, domestic violence, sexual abuse, addiction, and poverty. All had experienced remarkable transformations that had placed them on their "healing journeys." Two had completed their bachelor's degrees in social work, and two had completed relevant human services coursework.

Clients. Eleven clients who had already concluded their treatment in the program participated in the study. Eight of these were actual graduates of the program, representing perhaps half of the total pool of program graduates during the preceding years. Seven were men. Five were in their 20 s, four were in their 30 s, and one each was in his or her $50 \mathrm{~s}$ and $60 \mathrm{~s}$, respectively. Eight of the clients were single, and only the two youngest men reported no children in their lives. Most of the clients were struggling to cope with their own chaotic life circumstances when they began treatment in the program. Some agreed to participate in the program by arrangement with the courts or child protective services. Only two of the clients had personally experienced residential school, but the remaining individuals knew relatives who had experienced these repressive institutions. In fact, virtually everyone in the community had been touched in some fashion by the "intergenerational legacy" of the residential schools, and thus all were deemed eligible for program participation.

Owing to recent discontinuity in program administration, precise numbers of program participants, including graduation rates over the years, were not available. Program staff selected clients for participation in the study. Although there may have been some interest in "showcasing" their most successful clients, the logistics of recruitment-including locating, reassuring, and transporting former clients for their interviews-played an important role as well. As a result, the interviewed clients are not likely to represent the scores of community members reached by the program over the years. If anything, this group is likely representative of those for whom the program was most effective, as many of them participated for the full treatment cycle and even graduated from the program. In this regard, they remain the exception rather than the rule. Thus, their considered reflections concerning the therapeutic services they received most likely cast these in a somewhat positive light. Although questions of 
program efficacy would certainly be complicated by such sample bias, this article is primarily concerned with explicating the staff-driven incorporation of Aboriginal cultural practices into treatment services. It therefore remains unlikely that client sample bias would significantly alter any of the stated conclusions.

\section{Measures}

The primary source of data was semi-structured, openended interviews conducted by the author with the participants. Interview protocols were designed by Waldram (2008) for mutual adoption in the five AHF case studies. One protocol was designed for program counselors, while a similar protocol was designed for program clients. The counselor protocol first solicited the life narrative of the "therapist" or "healer," and then outlined 40 additional questions pertaining to the meaning and facilitation of healing (26 queries), training in therapeutic practices (4 queries), and therapeutic activities and client interactions (10 queries). The client protocol first requested demographic information (15 queries) before soliciting a life narrative. Subsequent questions pertained to the meaning of healing ( 7 queries), treatment experiences (6 queries), and qualities of an effective therapist or healer (17 queries). Both interview protocols were explicitly developed for flexible administration, using a conversational style.

Owing to time constraints, no respondent was asked every question, but all respondents were invited to reflect on the various domains of interest. The program coordinator and committee representative were interviewed using the counselor protocol because both were trained as counselors. The current and former executive directors of the Lodge were interviewed together in open-ended fashion relative to a host of informal questions arising during the study. The duration of the interviews ranged from $30 \mathrm{~min}$ to more than three and a half hours. Staff interviews were considerably longer than client interviews. All interviews were audio recorded, transcribed, and checked for accuracy prior to data analysis. Three additional sources of dataparticipant observation, program documents and records, and extant ethnographic materials for this rather populous northern Algonquian people-were used as an important means to properly contextualize interview material.

\section{Procedure}

Prior to the author's arrival on-site for the study, community permission for the project was negotiated, and approval by the controlling Institutional Review Board was obtained. Participant observation in the daily activities of the program staff afforded intimate familiarity with program activities. Formal interviews with respondents were arranged as logistics allowed. All respondents provided written informed consent to participate in the interviews and received university-branded apparel as compensation. Interviews requiring more than a single session to complete occurred in two instances. Notes concerning important aspects of program activity and structure were crafted throughout the study. Copies of documents and records associated with the counseling program were also retrieved for future reference (e.g., lecture materials).

On return from the field, interviews were transcribed by assistants and analyzed by the author. "Conventional" thematic content analysis (Hsieh and Shannon 2005) of interview transcripts was undertaken for the purposes of inducing common themes in respondent discussions of healing relative to stated research questions. The qualitative data analysis software program NVivo 8 was used to facilitate the coding of textual material and the derivation of themes within a conceptual hierarchy of nodes and trees representing the relationships between themes (Bazeley 2007). A thorough descriptive report was drafted and submitted to Lodge administrators and program staff for review and comment. The final revised report was formally submitted to the AHF in October of 2006. This official report (Gone 2008) comprises a comprehensive archive of the study, preserving details of both method and data that cannot possibly be included in the usual disciplinary venues for page-limited empirical publications. One key limitation of the official report, however, was its crafting in response to an overtly descriptive mandate by the AHF; alongside a companion article (Gone 2009a), a more robust analytical engagement of these data is offered here. Finally, an early version of this article was circulated to program staff for comment, resulting in an affirmative response (E. Azure, personal communication, October 27, 2008).

\section{Results}

Three primary themes emerged from the interview data with relevance for understanding how Aboriginal cultural practices were incorporated into the counseling program. These primary themes (or "parent nodes")-themselves comprised of secondary ("child nodes") and sometimes tertiary themes ("grandchild nodes")-were labeled as follows: Orchestrating the Therapeutic, Traditional Ways, and Healing Discourse. Relevant aspects of all three primary themes will be reviewed insofar as they speak to the incorporation of Aboriginal practices within this treatment setting as well as to the potential for cultural analysis to contribute to community psychology. Predictably, counselors and administrators were more adept than clients at discussing treatment approaches, so theme derivation 
depended somewhat more heavily on staff interview responses. Finally, pseudonyms have been adopted for attribution of quotations; administrator pseudonyms begin with $M$, counselor pseudonyms begin with $T$, and client pseudonyms begin with $A-K$.

\section{Orchestrating the Therapeutic}

The objective of any treatment center is to engage its clientele in therapeutic processes toward recovery. In this instance, the Lodge sought to do so through all of its programs in a distinctively Aboriginal oeuvre. Indeed, one stated goal of the counseling program was "to provide an integrated and holistic therapeutic approach to healing and wellness for individuals, families and the community utilizing western and aboriginal practices" (italics added). The administrators and counseling staff were energized and engaged by the opportunity to provide culturally integrated services-explicitly marked as such-for their Aboriginal clients. In fact, just prior to the beginning of data collection, the Lodge staff adopted new mission and vision statements that overtly reflected these cultural commitments. One administrator observed:

Even our [Lodge] statements, we wanted to make them unique to the Aboriginal. That's why we said [in our mission statement], "Paving the red road to wellness." That's why we said [in our vision statement], "Medicine Wheel firekeepers empowering healthy lifestyles." We're going to put that [symbol of the] Medicine Wheel there because we don't just want a vision statement that any white person can use. We want it to be unique...so...they'll know it's an Aboriginal vision statement. (Marge, Admin)

A second administrator elaborated: "I mean those statements are memorable. They're embued with the symbolism of our people" (Mike, Admin). How, then, was this self-conscious commitment to the "unique" cultural engagement of Aboriginal clients in therapeutic recovery undertaken? In response, two secondary themes from the interviews will be summarized.

Therapeutic Activities. A wide variety of programmatic activities was described by staff and clients, including both client-based and community-based activities. Regarding client-based activities, the structural backbone of the program was the "lectures" provided by counselors on most weeknights. Comprised of psychoeducational, expressive, and applied components, these lectures introduced relevant topical material for increasing client awareness and engaging client participation in the therapeutic process. As one client recounted, "The counselors will lecture us about different areas like alcoholism, drug abuse. They'd show us videos. We'd write. They'd give us exercises. Things like that. Kept me busy" (Clare, Client). Lecture topics included a combination of both Aboriginal cultural orientation (e.g., seven sacred directions, community values, residential schools) and mainstream "life skills" instruction (e.g., alcohol and drugs, self-esteem, communication skills). For example, the lecture on residential schools might include a formal topical overview; a film portraying residential school experiences; an exercise in which clients traced the consequences of residential schooling for their own families; and a sharing circle in which clients take turns voicing their reactions. Interestingly, the Aboriginal content of these lectures was presented to clients in order to expose them to a history and culture from which many had been inter-generationally alienated, just as architects of the residential schools had intended. As one client explained, "I learned a lot there, too, [about cultural ceremonies such as] sundances, sweats. I made [Native crafts, like] dream catchers. It was alright" (Joe, Client).

Beyond the lectures proper, clients were encouraged to participate in weekly one-on-one counseling sessions with staff members to further express and explore their reactions to lecture material and other aspects of the treatment process. One client expressed his appreciation for these one-on-one sessions as follows:

My counselor has been patient. I know she had some other things to do, but she gave me that time. She gave me her listening ear. She was understanding. Very encouraging.... She wasn't critical. She wasn't being judgmental.... Sometimes I would speak, and she wouldn't cut me off. Some counselors do that.... You never get to finish your story, and after a while you don't want to talk no more. She wasn't like that. (Ed, Client)

Counselor availability for private consultation in moments of crisis was important, too:

I had that urge to go to the bottle. But I said, "Never mind. Not this. I'll just go run to [my counselor]." And I came to [him]. And I think I cried a little when I talked to him. And then he said, "Well, it's a good thing you came." But he understands.... He talks to me real good. He made me feel better. I don't have to turn to the bottle. (Dawn, Client)

In sum, client needs would have been poorly served had their counselors kept "bankers' hours."

Regarding community-based activities, program staff organized and sponsored therapeutic workshops, associated fieldtrips, and cultural activities. Workshops differed from lectures in terms of their duration, intensity, and target audience. Scheduled for an entire day or more, counselors were able to address a pressing therapeutic topic and engage participants in much more depth than an evening 
lecture might afford. For example, workshops on grief and loss might incorporate an exercise in which participants draft a detailed letter to a deceased love one conveying previously unexpressed final sentiments. At the conclusion of the exercise, participants retire to peaceful outdoor settings where they pray, bid their loved ones farewell, and burn their letters, scattering the ashes into the lake or forest. Popular with clients as well, this exercise was reported to yield powerful therapeutic results: "Four of us were there. I read [my letter] out loud. And something lifted out of me. Because it was always in there. I've never told anybody how I felt. So it was good. I just felt so good after that" (Clare, Client). Within the context of additional formal consideration of grief and loss, such workshops allowed counselors to bring the therapeutic process out of the treatment setting proper to anyone in the community desiring such services.

Beyond these occasional workshops, program staff also organized intermittent fieldtrips for clients and community members to regional Aboriginal conferences. One series of fieldtrips included visits to former residential schools where, in the context of associated healing activities, survivors found relief and validation. Finally, program staff also hosted cultural activities for the community, including powwow dances, pipe ceremonies, and an annual fasting camp. Although clients were always encouraged to participate, staff strove to engage community members at large in these activities as part of a collective healing process. Such engagement could yield powerful effects, as this client explained:

This is where I started my healing journey. And this is where I practiced my Native culture. I go to sweat [lodge ceremonie]s, I go to fasting [camp]s, I go to powwows, and participate. It's a good feeling when you're starting to find your identity. To have that sense of belonging... and to have that identity in the purpose of life. (Ann, Client)

Interestingly, client concerns about confidentiality relative to involvement in community outreach activities seemed largely absent, perhaps because client participation in the program was virtually impossible to keep secret anyway within this close-knit, face-to-face community.

Therapeutic Modalities. "The counselors [are] people that have been there before and know how to work with our own people. The traditional and cultural part of it. But also I'm sure they're implementing some western stuff.... It's a combination" (Meg, Admin). Clear delineations were made by program staff between western and Aboriginal therapeutic approaches that were adopted for use in Lodge programs. The content of the lectures already described affords some glimpse into this self-conscious cultural distinction. With regard to the former, one administrator explained: "The western processes that we definitely want to keep...are [based on] the spiritual program that's regarded around the world as one of the best of its kind at helping alcoholics" (Mike, Admin). Thus, unsurprisingly, the Twelve Steps of Alcoholic's Anonymous (AA; see Wilcox 1998) furnished the therapeutic basis for program efforts. Beyond AA proper, the variety of therapeutic interests and approaches endorsed by program counselors-though not necessarily formally instituted into the program - was quite eclectic. Interestingly, almost none of these approaches enjoyed widespread professional sanction but instead hailed from popular psychology and alternative or New Age medicine: inner child explorations, guided imagery, meditation and visualization, anger discharge, acupuncture, neurolinguistic programming, genogram mapping, reiki, energy work, and cosmo therapy. In addition, concurrent community consultation with a South Korean economic development guru led to counselor enthusiasm for the "seven sacred shakras" and the therapeutic potential of "stillness, space, and gravity." In contrast to evidence-based practices for substance abuse or trauma, counselors seemed most interested in therapeutic approaches grounded in some form of "spirituality." Indeed, the openness and enthusiasm of counselors toward a diverse array of esoteric spiritual therapies were striking. In this regard, the significance of the administrator's characterization of AA as an overtly "spiritual program" was telling.

In contrast to the Western approaches that informed programmatic activities, various Aboriginal approaches were also in evidence in the counseling program. Counselors celebrated and sponsored prayer and "smudging" (i.e., purifying oneself by burning sacred plants), talking circles, tobacco offerings, pipe ceremonies, sweat lodge rituals, fasting camps, and various other blessing rites (e.g., ritual renewal of the colored cloths that marked the directional entrances to the Lodge). Facilitation of such overtly religious activity required special sensitivity:

Usually we would open our meetings... with a prayer.

Because we have different [Christian] denominations in our community..., and then we have what we call our traditionalists..., we don't pray any certain way. We don't pray the Catholic way [or] the Anglican way.... We pray in the same way that you'd be talking to a friend.... We don't ask for favors, and we don't ask for miracles.... We just give thanks. (Tom, Counselor)

These religious or ceremonial activities were formally instituted in Lodge programs in several ways. First, Aboriginal culture and tradition featured overtly in the lecture materials. Prayers, smudging, and talking circles were routinely incorporated into evening lecture activities 
and community workshops. Second, program counselors were involved in sponsoring cultural activities for the community (e.g., a pipe ceremony in honor of residential school survivors).

Third, the Lodge employed a full-time "traditional counselor" whose responsibilities included the formulation and facilitation of additional cultural activities within standard treatment regimens. For example, the traditional counselor conducted a sweat lodge ceremony every Thursday afternoon for clients. Finally, nine of the staff at the Lodge-including the majority of the counseling program staff_-identified as "pipe carriers," which means that they had obtained the right and responsibility to ritually care for and pray with a sacred pipe. As a result, client encounters with Aboriginal culture and tradition-even though full participation was strictly optional-were routine. Some clients had never participated in these activities prior to their time in the program: "Because the first time I smudged, it just felt different. My body felt different.... You just felt so light. Man, did that just make me feel better about myself!" (Ike, Client). It was this incorporation of cultural and ceremonial tradition that marked the Lodge, according to one administrator, as a "regional center" that was "looked upon a lot for the Aboriginal way of practices" (May, Admin).

By way of better appreciating the therapeutic effects of these Aboriginal approaches, consider the in-depth description of the sweat lodge provided by one counselor:

It's a sacred ceremony. And it addresses all four areas of our being. It cleanses physically, mentally, and emotionally and spiritually. Because in our cleansing ceremonies...we have that opportunity to share with one another whatever it is that's bothering us. Whatever it is that's not right in our lives, that's hanging over our shoulders.... It gives us that opportunity to release that there.... (Tom, Counselor)

Note here the emphasis on "cleansing" across four domains of experience. Moreover, participation in "sharing" was discussed in terms of a "release." The counselor continued:

If we're sincere about the ceremony itself, we come out of there feeling refreshed.... The physical tiredness you feel,...it's a tiredness of releasing a heavy load. That kind of relief. Mentally, you feel okay because then you come to the realization that, "Hey, I'm not the only one with this problem. And yeah, I can see how I can work this problem out"... And you have the support of all those people...in that circle. (Tom, Counselor)

The potentially salutary consequences of ceremonial participation were evident here, including the centrality of "sincerity" for achieving the therapeutic benefits of refreshment, "relief," "realization," and mutual "support."

Theme Summary. Analysis of interview transcripts, as contextualized by other sources of data, reveals that effective treatment in general was understood to require a "spiritual program." The tried and true approach of AA was adopted as the basis for therapeutic activities in Lodge programs, but only as configured in relation to a diverse set of alternative spiritual therapies. In contrast to various western modalities, one set of these approaches was marked as distinctively Aboriginal. More specifically, as counselors sought to orchestrate the therapeutic for their clients and the broader reserve community, they selfconsciously engaged in the incorporation of Aboriginal approaches and practices into their more conventional treatment efforts, effectively institutionalizing several of these. Particularly in the lectures, introduction and consideration of Aboriginal cultural content was seen as an overt effort to familiarize potentially anomic clients with their own cultural heritage: "With the traditional lifestyle and all that stuff,...I just stopped believing...in all that stuff. Like I didn't care.... After a while, this program here, it opened my eyes pretty good [to the importance of these things]" (Karl, Client). Beyond this, intermittent Aboriginal cultural and ceremonial activities were supported, sponsored, and promoted by program staff.

Taken together, these therapeutic efforts were addressed not just to "psychiatric symptoms" or "personal problems," but instead to the "cultural renaissance of the Red Man" (as described in the article's opening quotation). In short, Aboriginal identity was highlighted as a key casualty of the colonial encounter. The pathogenic force of this "monster called identity" (i.e., the contemporary result of historically orchestrated anomie) resounded in client and community lives, and this legacy of the residential schools was seen to require careful remediation as well. In this sense, the therapeutic efforts of the counseling program clearly extended well beyond the usual confines of a "treatment" center to the vibrant promotion of community wellness in spiritual, existential, and cultural terms:

I was an alcoholic. Washed up, too!... When I came here for treatment that time, then I learned [about addiction]. This is where I learned my culture, too. And this is where I started healing. And last year when I completed the program, then that's when I returned to university. And here when I started working, I became a...therapist.... I used to be ashamed for being an Indian.... I'm proud to be a Native now. I'm proud for who I am. I know my identity. (Ann, Client)

In sum, the programmatic activities of the counseling staff were comprised of both western and Aboriginal 
therapeutic modalities harnessed together for a community targeted healing intervention. Recall, however, that the stated goal of the counseling program was "to provide an integrated and holistic therapeutic approach." And so, beyond mere incorporation of Aboriginal cultural traditions and practices into conventional treatment approaches, it is worth briefly considering whether and how such approaches were effectively merged into a coherent whole. That is, in what ways was the potentially resultant therapeutic hodgepodge packaged or streamlined into a unified philosophical approach to Aboriginal treatment?

\section{Traditional Ways}

A second primary theme that emerged from the interviews concerned "traditional" matters more generally. For example, this theme subsumed material regarding the Aboriginal cultural revitalization that began in the 1970s, and the mild conflict that sometimes arose between staff regarding issues of cultural authority, authenticity, and distinctiveness. Owing to space constraints, only one secondary theme will be discussed here, namely the Medicine Wheel. In a literal sense, medicine wheels are rock formations found throughout the Canadian shield that were built by Aboriginal peoples long ago for presently unknown purposes. In a symbolic sense, the medicine wheel has become a pan-Indian icon with widespread adoption and recognition as a depiction of a distinctively indigenous philosophy (Dapice 2006). Programmatic promotion of this pan-Indian conceptual framework made sense because, even though the outpatient program served residents of a single local tribal community, the Lodge served as a regional provider of inpatient substance abuse treatment services for a wide range of Aboriginal people throughout the western Canadian provinces (see also Waldram et al. 2008).

Variations on the symbolic portrayal of the medicine wheel abound, but the basic components include a circle bisected by two perpendicular lines, creating four internal quadrants. Conceptually, this symbol was said to represent the holistic balance and integration of four constituent parts within a unitary totality. The symbol affords both spatial and temporal representations. The prototype for the spatial representation is the four "sacred" cardinal directions, while the prototype for the temporal representation is the four seasons of the year. As a result, the medicine wheel images the unity of directional space and cyclical time within a coherent whole. Thus, the evident conceptual contribution of the medicine wheel seems to be an explicit recognition that any element considered in detached isolation from the other three distorts reality, yielding disharmony and disintegration.

It is this symbolic representation of a philosophical approach that was referenced in the mission and vision statements of the Lodge. One administrator elaborated: "The medicine wheel takes in everything that we know, have known, and can accommodate what is to be known. The medicine wheel is that encompassing" (Mike, Admin). The range of phenomena that were "accommodated" to the medicine wheel was striking, as a second administrator observed:

The red, white, black, and yellow [quadrants] in the medicine wheel, it each symbolizes something. There's an animal that sits in each direction, and it symbolizes that love, humility, and [other values]. And then there's a plant [associated with each direction]. So it shows everything is...interconnected.... That we're all equal. (Marge, Admin)

For therapeutic purposes, the medicine wheel was adapted to the holistic and cyclical aspects of human experience in particular.

More specifically, the four quadrants were associated with the physical, mental, emotional, and spiritual aspects of human experience: "You hear about the body, mind, spirit, and emotions. All about that.... That's what [the program] is mostly about" (Hal, Client). Additionally, the circumference was understood to represent the human lifespan that cycles through four stages of development from neonatal dependence on others to the late-life dependence of the elderly: "For myself, [the medicine wheel is] four directions.... And going around, it's from birth, to youth, to adult, and to an elder. In a circle" (Beth, Client). Thus, in this therapeutic context, the medicine wheel mapped an Aboriginal topography of the self. One counselor discussed the significance of the medicine wheel for the therapeutic activities of the counseling program in detail:

The medicine wheel is a concept. It's an idea. It's a philosophy. It's not something that you can carry around with you in your pocket.... You can use that concept.... You can use those teachings in every aspect of your life because it includes the whole universe.... We are but a speck of that whole universe, but we are interrelated.... The medicine wheel teaches us...about all of our being. Not just our mental, not just our physical, not just our emotional, not just our spiritual, but all of it. (Tom, Counselor)

Again, the significance of interrelationship between constituent parts was emphasized. Indeed, the conceptual thrust of the therapeutic project in Lodge programs was to promote client awareness of all four aspects of the self and to facilitate the pursuit of balance among these facets of experience through healthier lifestyle choices.

Within this pursuit of harmonious selfhood lies the integrative power of the medicine wheel approach to healing. For despite interest in and adoption of a wide variety of 
therapeutic approaches-whether western or Aboriginal in origin-each was subsumed to the overarching orientation to selfhood (and associated therapeutic tasks) represented by the medicine wheel. As a consequence, even the western approaches were structured within an overtly Aboriginal frame of reference. Unsurprisingly, then, the medicine wheel featured prominently in the mission and visions statements of the Lodge and in the discourse of program staff and clients. Indeed, the medicine wheel philosophy signified at the highest order of abstraction the Aboriginally distinctive therapeutic endeavor undertaken at the Lodge. Its adoption and promotion was selective, self-conscious, and expressive of a distinctive "postcolonial" politics that sought to re-center Aboriginal thought, life, and purpose within a reserve-based treatment context ("We don't just want a vision statement that any white person can use" [Marge, Admin]). In contrast to this higher-order, selfconsciously promoted Aboriginal therapeutic discourse, however, a more fundamental and implicit non-Aboriginal therapeutic discourse was advanced as well.

\section{Healing Discourse}

The final primary theme to be reviewed here was the most nuanced and complex of the three, and will be explicated here only insofar as it illuminates the meaning of healing as understood and practiced in the counseling program (for elaboration, see Gone 2009a). In particular, this section will focus on the tacit or implicit meaning of healing that was nevertheless in abundant evidence in the interviews with staff and clients. This evidence demonstrates that healing essentially indexed the power of talk to purge personal pain toward the refashioning of a more functional self. Three secondary themes were seen to comprise an implicit healing discourse - perhaps best glossed as a form of the "talking cure" - that might be summarized as follows.

First, the therapeutic utility of talk was grounded in the belief that program clients "carried" deep personal pain as a result of traumatic experiences earlier in life. These experiences frequently were attributed to colonial disruptions of community life (e.g., "from the Western society, colonizationists, Europeans" [Beth, Client]), including the atrocities of the Canadian residential school system. The resultant emotional "burdens" were understood to weigh heavily on client lives, continually overloading or derailing individual efforts to find purpose and happiness, as in the "heavy load" referenced earlier in a counselor's description of the sweat lodge that indexed "whatever it is that's bothering us...that's hanging over our shoulders" (Tom Counselor). One administrator elaborated as follows:

Some of [our Aboriginal people] experienced... abuse.... Because of those experiences, a lot of them never recovered.... They never dealt with their issues.... And some of them have never had an opportunity to talk about what they experienced.... They kept it inside. And then it just built up like a pressure cooker. (Marge, Admin)

The key concept here was that past personal pain, if unconfronted or unexpressed, can undermine present-day functioning: "Oh, it affected me a lot. Especially, years [later] when I came home, I was abusive myself because of what happened to me over [in residential school]" (Frank, Client). Thus, in order to gain relief from such harmful burdens, "dealing with" or "facing head on" one's traumatic past was required.

One prescribed means to releasing these burdens was cathartic verbal expression. Thus, secondly, healing required above all the "release" of painful emotional burdens through the acknowledgment and confession of past ordeals. One client explained how his counselor had assisted him in this process:

[My counselor] encouraged me to...talk. Bring it out. Even if I felt it wasn't necessary to talk about this story.... I always felt silly about...being [sexually molested by a nurse].... I didn't really talk about those things before.... But it taught me how to express...how I really felt inside me, and bring it out. And that really helped. It took a lot of weight out of my shoulders... when I was finally able to cry in front of [the group]. (Ed, Client)

The key concept here was that the suppression and denial of personal pain could only yield misery and pathology, while the disclosure of personal pain and the resultant emotional catharsis might yield release and healing: "I totally forgot about my being [in treatment] for the courts.... [For the] first time, I was giving it a chance, you know? But then I started talking and talking. All these emotions started coming out. Crying, laughing, crying" (George, Client). With the exception of a single client, there was utter consensus on this point in the program. One counselor said it best: "A lot of those people [out] there need one-on-one counseling. Talk to [Ted]. Let's dig it out.... Let's begin our healing journey" (Ted, Counselor).

Of course, none of the program staff and clients claimed that disclosure and catharsis was the sum total of healing. More specifically, cathartic self-expression was expected to inaugurate a process of searching reflexivity and selfexamination that could sustain positive and ongoing transformations of the self. Thus, thirdly, healing required a form of introspection that rendered the self as a therapeutic project. In colloquial terms, "looking at" oneself seemed necessary for healing, as this counselor observed: 
So that's what they learn here in [our program], is that they need to take responsibility for their own lives. And sometimes, yes, it's good that they're forced to take a look at themselves. Because sometimes we have to be forced.... And once they're able to look at where they came from...they learn different ways on how to cope. (Tia, Counselor)

Such searching self-examination could only yield deeper insights in service to positive self-transformation. In essence, then, a refashioning of the self became the therapeutic "project" that required consistent attention, inspiration, and insight. Thus, "working on" oneself, one's "issues," or one's life was emblematic of the healing journey that signified a lifelong process of introspection, transformation, and fulfillment:

Okay, I'm sober. Good. But little did I know that I had to go further. To have that healthy lifestyle you've got to look at your attitude, your thinking, your behavior. You've got to look at yourself emotionally, mentally, physically, and spiritually in order to have that balance of living. (Ann, Client)

With regard to this aspect of healing, key concepts that emerged were self-examination, self-awareness, and a willingness to work on oneself.

The meaning of healing as it was understood and practiced by staff and clients in the counseling program might be summarized as the ongoing process of positive self-transformation-fueled by introspection, reflexivity, insight, disclosure, catharsis, "dealing with" one's problems, "working on" oneself, and finding one's purpose as an Aboriginal person-that ultimately reoriented fragile and often damaged selves toward a more meaningful and compelling engagement in the world. Interestingly, the most implicit aspects of this healing discourse reinforced widespread, popular notions of the therapeutic value of verbal disclosure and resultant emotional catharsis. Most important for the purposes of cultural analysis, it must be observed that client participation in the disclosure-catharsis dynamic seemed strikingly difficult to orchestrate. In fact, both counselors and clients expressed anxiety about embracing and promoting the talking cure. Counselors noted how challenging it was to get their clients to talk in group meetings or in one-on-one counseling:

Our Native people have such a hard time talking about their emotion. How they feel. And I've seen that from as far back as I can remember.... It's just recently that I've been able to talk about how I feel.... Having worked in the last...fifteen years in social work... with our...Native people, I find it's like pulling a tooth out of them. (Tom, Counselor)
Clients recalled extreme discomfort in the face of staff expectations concerning therapeutic talk:

Like [this one counselor] didn't come on too strong. Not like other people, [who urge] "Come on, you got to spill it out. Let it out. Let out." Like, I just got here anyway! [Laughs] I don't hardly know you guys. (Hal, Client)

Moreover, the difficulties associated with eliciting therapeutic talk from clients was attributed in part to enduring community norms that devalued or proscribed such verbal self-expression. And yet, despite these challenges, healing was consensually understood to require client engagement in such therapeutic talk.

\section{Discussion}

One goal of this study was to analyze how Native American cultural practices were incorporated into an outpatient counseling program within a First Nationcontrolled community treatment setting vis-à-vis the interests and commitments of community psychology. By way of summary review, this analysis yielded four findings. First, the Healing Lodge was seen to center and to celebrate the distinctive Aboriginal character of its programs. Indeed, the mission and vision statements of the Lodge refer to pervasive Aboriginal symbols and practices, and programmatic services were self-consciously tailored to the "unique" needs of an Aboriginal clientele. This distinctiveness afforded therapeutic attention to a wider range of historical, cultural, and existential matters in the lives of clients than treatment-as-usual. Second, program staff grounded their therapeutic efforts in the Western approach of AA, an overtly "spiritual program," as influenced by ready interest in a range of complementary and alternative therapeutic methods that share in common their emphasis on "spirituality." Alongside these approaches, a variety of Aboriginal practices and ceremonies were institutionalized in the treatment setting, though client participation in these was strictly voluntary. Moreover, these diverse therapeutic efforts of the program staff were deliberately extended beyond the roster of official program clients in order to reach a much broader swath of the reserve population, effectively disrupting the boundary between professional treatment and community renewal.

Third, the adoption of both Western and Aboriginal therapeutic approaches was consolidated into a coherent therapeutic endeavor through the subsuming of these diverse modalities within the overarching philosophy of the medicine wheel. For therapeutic purposes, the medicine wheel afforded a topography of the self that enabled staff and clients to strive for balance and harmony between the 
physical, mental, emotional, and spiritual aspects of human experience. Moreover, adoption of this higher order therapeutic framework preserved and promoted the distinctive Aboriginal character of Lodge programs, effectively expressing a postcolonial re-articulation of long suppressed Aboriginal lifeways and worldviews toward greater community healing. Finally, in contrast to the self-consciously selected and rhetorically effective celebration of recognizable Aboriginal symbols and practices at the Lodge, healing discourse among staff and clients was also seen to depend heavily (but implicitly) on more familiar aspects of mainstream "therapy culture" (Furedi 2004; Moskowitz 2001; Polsky 1991; Ward 2002). More specifically, the lower order (and mostly latent) practice of healing by program staff appeared to involve the targeted facilitation of cathartic verbal expression, the release of deep personal pain, and the inauguration of a "healing journey" in which the self becomes a therapeutic project in need of lifelong attention, introspection, and inspiration.

Of course, the overarching objective of this article is to illustrate how cultural analysis (i.e., critical engagement of empirical observations motivated by cultural interests) might advance inquiry within community psychology proper. Interestingly, community psychology is no stranger to Native North American well-being. In fact, several articles concerned with tribal communities have appeared in the pages of this journal since its inception, including critical reflections on the opportunities and challenges confronting mental health programs and services within indigenous settings. McShane (1987) provided an overview of "critical issues" in this regard. Mohatt et al. (2004) while implicitly subscribing to principles of tribal participatory research described earlier by Fisher and Ball (2003) — sought to identify more effective strategies for alcoholism prevention and treatment among Alaska Natives by undertaking "culturally anchored" methods for exploring community-distinctive pathways to sobriety. Their substantive consideration of the Yup'ik notion of Ellam-iinga was just one of the many adaptations required for conducting culturally valid research with these populations. Based on his interview with a Gros Ventre "traditionalist," Gone (2007) concluded that similar attention to indigenous cosmologies was necessary if mental health programs and services were to be re-imagined so as to neutralize their potential to effect a "western cultural proselytization" of Native clients.

With regard to therapeutic intervention per se, perhaps the most relevant article is also one of the earliest. Kahn et al. (1975) reviewed the approaches and activities of a tribally-controlled community mental health clinic on the Tohono O'odham reservation in Arizona (for a follow-up, see also Kahn et al. 1988). Although the article was principally devoted to the presentation of a locally-tailored service model, its brief discussion of psychotherapy with O'odham (formerly known as Papago) community members resonates here:

Most Papagos loathe discussing personal information with anyone, and doing so with strangers is certainly most uncommon. The paucity of verbal communication (as compared to the Anglo) is another variable which has considerable influence on therapeutic methodology. Impressionistically, it seems the Papagos really aren't very verbose among themselves and certainly not with Anglo professionals or, if you will, authority figures. (p. 92)

Even this published description, however, remains summary and impressionistic when it comes to empirical explication of therapeutic processes and practices within Native-controlled treatment settings. Given widespread professional interest in "culturally competent" treatments and services, it is thus surprising that careful empirical descriptions of efforts similar to the one described in this article have yet to appear in the psychological literaturewithin or beyond $A J C P$-in any substantial fashion, presumably qualifying the present study as a modest contribution in its own right in this regard.

It remains, however, to analytically "unpack" the interpretive conclusions of this article for the purposes of illustrating the promise of cultural analysis for community psychology. Four kinds of contributions will be described in turn. First, cultural analysis enables community psychologists to empower culturally marginal and historically oppressed groups by centering the perspectives and interests of group members in empirical reports and associated disciplinary publications. In order to achieve this representational aspiration of "giving voice" to those who have been routinely silenced or "spoken for," community psychologists must attend to the "emic" (or locally grounded and culturally emergent) aspects of meaning making. In so doing, community psychologists will be able to portray their respondents' actions in local terms as well as to properly contextualize such actions within an intelligible frame of reference for a scholarly audience. By now, it should be clear that one goal of this article has been to represent the therapeutic interests and commitments of program participants at the Lodge relative to staff activities with Aboriginal clients. Most evident with regard to these activities was the adoption and promotion of a self-conscious discourse of "culture" that was routinely expressed and deployed to mark programmatic efforts as distinctively Aboriginal in orientation. Within the systematic historical context of national ethnocidal policies and institutions (especially the residential schools), the postcolonial project of reconstituting Aboriginal worldviews and lifeways would seem to require a robust consideration of the cultural 
past as well as a contemporary re-articulation of this past that accords with present-day realities. The staff and programs at the Lodge represent an exemplary instance of facilitating a postcolonial project of cultural reclamation within a "treatment" setting that manages to extend far beyond its own doors into the homes and hearts of many non-treatment-seeking community members.

Nevertheless, the therapeutic emphasis on cultural identity and practice presents a substantive challenge for community psychology as well, especially with regard to questions of therapeutic efficacy. Twenty years ago, Weibel-Orlando (1989) provocatively observed that anthropologists who partner with indigenous communities to study locally-responsive treatment programs for alcohol problems were "hooked on healing": "We tend to assume the efficacy of indigenous healing practices. We value indigenously-developed alcohol addiction intervention strategies as inherently preferable to imposed intervention models" (p. 149). In order to truly assist Native communities in these efforts, however, she concluded that it was time "to ask systematic, hard-nosed, and pragmatic questions. First and foremost, we need to ask about efficacy" (p. 153). More recently, Brady (1995) expressed similar concerns about the assumed benefits of indigenous cultural approaches for substance abuse treatment-many of which had been imported from North America to her Australian context-within indigenous communities. These critiques serve to remind researchers and community members alike that popular interventions are not necessarily efficacious interventions, and that treatment outcomes remain a matter of empirical inquiry. For example, it seems striking that the Lodge's outpatient program had been operating for several years and yet had managed to guide so few clients to program completion. There are several potential explanations for this, but given its visibility as just one component of program efficacy, additional rigorous inquiry into such matters would seem to be important. Detailed discussion of these issues appears elsewhere (Gone 2009a), but for present purposes it should suffice to observe that questions pertaining to therapeutic benefits should be investigated with an eye toward community-designated criteria for targeted outcomes.

Second, cultural analysis enables community psychologists to attend to the subtle but significant cultural aspects of diverse psychological phenomena. That is, in contrast to the self-conscious discourse of culture observed in this northern Algonquian treatment setting, many of the most influential cultural processes and practices in any society are exercised and expressed in principally tacit fashion. Linguistic practice affords an illuminating case in point: whereas nearly all humans are socialized into language fluency, only a tiny subset of people are able to formally and comprehensively reconstruct the rules of such practice (e.g., grammar, syntax, communicative norms). Similarly, many other cultural processes and practices "fly under the radar" for those who practice them, and yet these remain open to formal explication by researchers who are trained to attend to them. In the present study, the higher order trappings of Aboriginal culture were self-consciously adopted and promoted at the Lodge, and yet there were also clear indications that certain lower order or latent-and yet still very influential-elements of healing discourse within the program were decidedly non-Aboriginal in origin. For example, the extant scholarly record attests to signature divergences in communicative norms that govern therapeutic talk on the one hand (Moskowitz 2001; Ward 2002) and normative instances of verbal expression and interaction for northern Algonquians on the other (Darnell 1988; Preston 1975). More specifically, Darnell (1981) has observed: "[For] most American Indian groups...public and private (intimate) behavior are sharply distinguished.... Talk in public is something to be monitored with great care.... Indians consider social interaction to be potentially dangerous, a face-threatening imposition on personal autonomy" (pp. 56-57). In other words, in this regard, cultural analysis of local healing discourse not only highlights the salient role that Aboriginal cultural "tradition" plays in Lodge programs, but it also illuminates the subtle and potentially divergent influence that western therapy culture exerts as well.

This intriguing expression of cultural hybridity likewise presents community psychologists with a significant challenge, for it renders possible a set of politically sensitive competing interpretations. On one hand, if in a postmodern age one's ancestry is less significant than one's travel plans (Shweder 1994), then cultural hybridity has simply become the way of the world: of course Aboriginal communities in modern North America have embraced therapeutic tenets that might be traced back to nineteenth century Vienna because so much of the western world has. Thus, according to this rationale, it is to be expected that contemporary Aboriginal peoples in these larger national contexts might find healing through locally-inflected variants of the talking cure. On the other hand, the Lodge staff was deeply committed to the "cultural renaissance of the Red Man," which they consistently and explicitly defined as a postcolonial reclamation of Aboriginal cultural orientations, assumptions, and practices. Particularly in light of data that suggest that Aboriginal clients were regularly uncomfortable with the treatment mandate to engage in prescribed therapeutic talk, to what degree is it appropriate for an outside researcher to entertain the proposition that this implicit emphasis on therapeutic talk-far from being carefully vetted and freely adopted-instead represented a lingering facet of the colonial legacy? Indeed, cultural norms that govern communication frequently remain tacit. 
As a consequence, what precisely would constitute adequate assurance that socialization into cathartic verbal expression of this kind was in fact an agentic and selfdetermined postcolonial synthesis of healing traditions rather than the neo-colonial displacement of enduring sociolinguistic practices that have constituted Northern Algonquian selfhood for centuries? In sum, with regard to such subtleties, community psychology will need to sort through which of these kinds of competing interpretations remains both faithful to one's observations and helpful to one's community allies.

Third, in response to the aforementioned dilemma, cultural analysis enables community psychologists to serve an important consultative function in partnership with community-based constituencies and organizations. From its inception, community psychology has aspired to engage "citizens" in the struggle for self-determination. Indeed, collaborations and partnerships with community members have become a signature hallmark of "action" research. Several ways that community psychologists might fulfill this responsibility involve "outward looking" activities such as undertaking political advocacy, pursuing external resources, garnering scientific legitimacy, or influencing social policy on behalf of community interests. One set of additional contributions, however, surrounds such "inward looking" activities as presenting research findings for community reflection and reaction. For example, in the present study, some implicit aspects of healing discourse promoted by staff appeared to be of non-Aboriginal origin. Specifically, the assumption that deep personal pain requires cathartic verbal expression in order to start a lifelong journey of self-awareness and introspection originates from modern "therapy culture" (Furedi 2004) and stands in stark contrast to historical-and even contemporary-northern Algonquian healing practices (Young et al. 1989). Of course, as was mentioned above, cultural hybridity is the way of the modern world, and no indigenous people should be imprisoned by a postcolonial nostalgia for a "pristine" pre-modern era. Furthermore, it is well beyond the mandate of community psychologists to wax prescriptive in this regard. Nevertheless, to the degree that program staff were simply unaware of the centrality of Western therapy culture in their efforts, and to the degree that northern Algonquian healing tradition might yet afford additional innovations within Lodge programs, reflection of analytic insights back to the community could indeed prove useful. Should Lodge administrators and staff decide to explore the prospects for greater cultural consistency in their programs, further cultural analysis of extant Aboriginal healing traditions might be of additional help as well.

The substantive challenge presented to community psychology by such consultative efforts is the potential for professional role ambiguity and associated dilemmas. More specifically, many community psychologists are appointed as academics and researchers who must teach and publish as part of their professional responsibilities. Thus, in addition to engaging in participatory research partnerships with community members, community psychologists must also exercise academic integrity in interpreting and reporting research findings. Alongside such commitments, however, community psychologists simultaneously strive to subvert the usual researcher-respondent relationship built on power differentials stemming from the documented credentials and recognized expertise of the investigator, instead embracing opportunities for community advocacy and the mutual exchange of valued knowledge. Despite such commitments to mutuality, within Native North America the zeitgeist is shifting such that externallyfunded research is increasingly controlled by tribal communities, some of which now require "approval" by tribal government officials of all research manuscripts based on studies conducted in their midst prior to their submission for publication. Some Native academics support this shift (Manson et al. 2004). And yet, if politicians or their appointees are accorded authority to unilaterally permit or proscribe (or simply edit) the written presentation of research findings prior to publication, then the integrity of these publications is compromised. In fact, this surrender of academic freedom-even in principle-as part of one's consultative role might be seen to undermine the very premise of academic inquiry. Of course, true partnerships of the kind celebrated by community psychology require intensive engagement surrounding the analysis and reporting of research findings, but this is clearly an arena in which probably infrequent but delicate negotiations must be managed less by default to bureaucratic procedure and more by interpersonal engagement on the grounds of a robust relational research ethics (Fisher 2007; Gone 2009b). It remains for community psychologists to work this all out with much greater nuance.

Finally, cultural analysis enables community psychologists to elucidate the workings of power in modern societies so as to more effectively promote the establishment of alternatives to the status quo. Attention to expressions of inequality and the implications of unjust social arrangements have inspired community psychology since the 1960s. In the present study, it is neither arbitrary nor accidental that Lodge programs dedicated to culturally distinctive interventions for widespread Aboriginal distress happen to privilege salient qualities of modern therapy culture. Instead, the presence of therapy culture within Lodge programs is a direct function of macrosocial arrangements in which relatively plentiful funding designated for health care remains a primary resource for redressing the colonial legacy in Aboriginal Canada. As Prussing (2008) has observed elsewhere, such funds are 
usually bound up within structures of authority and legitimacy that reinforce dominant cultural formations, such as preference for university credentials and professional licensure for health practitioners or accreditation for health services. As a result, staff members bring to their practice a host of cultural ideas and ideals concerning "health" and wellness obtained during their own early encounters with the substance abuse treatment sector and their later participation in formal training curricula. Such experiences frequently involve scant attention to Aboriginal issues per se. Moreover, accreditation pressures to conform to "high" organizational standards in service delivery are more likely to facilitate cultural uniformity rather than innovation. Suppose, for example, that Lodge administrators committed to hiring traditional Aboriginal healers in their programs. A host of epistemological, therapeutic, and administrative challenges would likely ensue, but additional cultural analysis of therapeutic settings and their relationships to larger societal institutions might illuminate pathways for more effectively negotiating power and its exercise in the face of such challenges.

Given the extremely durable quality of societal power arrangements, the substantive challenge for community psychology associated with the elucidation of such arrangements concerns the degree to which action researchers and their community partners might choose to "play the game" in their efforts to achieve community selfdetermination. Certainly, it was within the purview of Lodge administrators and their governing Board of Directors to decide whether meeting national accreditation standards was important enough to warrant conformity to mainstream therapeutic conventions in key instances. Of course, as I discussed above, the deck is stacked in such a way as to heavily constrain such choices, virtually assuring, for example, that Lodge accreditation would remain a high priority. More realistic in the face of such constraints is the range of compromises that nevertheless continues to afford considerable flexibility in the face of distant monolithic bureaucracies. For example, the strong commitment to community outreach by Lodge programs ensured a mingling of formal clients and community residents in some activities that pushed the limits of confidentiality well beyond the practices of most substance abuse treatment settings. Of even greater significance are those instances of sweeping national transformation wrought by organized campaigns of citizens at the social margins who demand a reconfiguration of the status quo. It should not be forgotten that the Lodge's outpatient program (and this research) was funded by the AHF, an organization created in response to Canada's national conversation on the status of its indigenous peoples through the public activities of the Royal Commission on
Aboriginal Peoples during the mid-1990s (Royal Commission on Aboriginal Peoples 1996). As a result of this commission's work, federal funds have been allocated for healing projects, the Prime Minister has offered a national apology, and a Truth and Reconciliation Commission has been established. Clearly, moments of societal transformation are sometimes possible, and attention by community psychologists to the macro-social workings of power can illuminate such arrangements in service to progressive social change.

\section{Conclusion}

This article explored the promise of cultural analysis for community psychology by investigating the incorporation of Native American cultural tradition within a First Nationcontrolled substance abuse treatment setting. Analysis of open-ended interviews with nineteen staff and clients of the Healing Lodge's counseling program-as contextualized by participant observation, program materials, and the existing ethnographic record-yielded three primary themes concerning therapeutic practice. In their efforts to orchestrate the therapeutic, program staff adopted and promoted a diverse array of western and Aboriginal approaches, most of which originated or depended on "spiritual" principles. The rather breathtaking diversity of these approaches was subsumed into a coherent therapeutic endeavor with reference to traditional ways; more specifically, therapeutic adaptation of the Aboriginal symbol of the medicine wheel marked Lodge programs as distinctively Aboriginal in character. Nevertheless, analysis of healing discourse in the program also revealed the subtle but profound influence of Western therapy culture in the healing activities of the program. Most importantly, the therapeutic aspirations of program staff extended well beyond their official clientele to include routine outreach so as to effectively blur the distinction between professional treatment and community renewal. Finally, cultural analysis of these therapeutic activities was seen to illustrate four potential contributions to community psychology: giving voice to marginalized communities, explicating subtle yet influential cultural aspects of psychological phenomena, reflecting community processes back to research partners, and elucidating structural relations of power in service to novel expressions of community selfdetermination. With its longstanding commitments to the psychological investigation of intersubjectivity, diversity, empowerment, and sociopolitical context, community psychology is uniquely positioned to undertake the kind of sophisticated and substantive cultural analysis so desperately needed by disciplinary psychology at the outset of a globalized twenty-first century. 
Acknowledgments This study was undertaken as part of the Models and Metaphors of Healing Project coordinated by J. B. Waldram. Completed under the auspices of the Canadian National Network for Aboriginal Mental Health Research (Laurence J. Kirmayer and the late Gail Guthrie Valaskakis, co-Principal Investigators), the overall project was funded by the Canadian Institutes for Health Research. The University of Michigan, Department of Psychology, provided the author with discretionary research funds and research office space to facilitate early analysis of the data. In addition, transcription costs were underwritten by the author's "research fund" provided to him during his tenure as a Kellogg Scholar in Health Disparities in 2003-2004. Both graduate and undergraduate students in the author's Culture and Mental Health research laboratory at the University of Michigan rendered invaluable assistance in gathering related scholarly materials and reviewing, correcting, and discussing project transcripts. Further data analysis occurred during the author's tenure as the 2007-2008 Katrin H. Lamon Fellow at the School for Advanced Research on the Human Experience in Santa Fe, NM. Finally, the author extends his gratitude to Mr. Ed Azure and Ms. Myra Hart for their support and cooperation throughout this research project.

\section{References}

Bazeley, P. (2007). Qualitative data analysis with NVivo. London: Sage Publications.

Beals, J., Manson, S. M., Whitesell, N. R., Spicer, P., Novins, D. K., Mitchell, C. M., et al. (2005). Prevalence of DSM-IV disorders and attendant help-seeking in 2 American Indian reservation populations. Archives of General Psychiatry, 62, 99-108.

Beiser, M., \& Attneave, C. L. (1978). Mental health services for American Indians: Neither feast nor famine. White Cloud Journal, 1(2), 3-10.

Borofsky, R., Barth, F., Shweder, R. A., Rodseth, L., \& Stoltzenberg, N. M. (2001). When: A conversation about culture. American Anthropologist, 103(2), 432-446.

Boyd-Ball, A. J., \& Dishion, T. J. (2006). Family-centered treatment for American Indian adolescent substance abuse: Toward a culturally and historically informed strategy. In H. A. Liddle \& C. L. Rowe (Eds.), Adolescent substance abuse: Research and clinical advances (pp. 423-448). Cambridge: Cambridge University Press.

Brady, M. (1995). Culture in treatment, culture as treatment: A critical appraisal of developments in addictions programs for indigenous North Americans and Australians. Social Science and Medicine, 41(11), 1487-1498.

Brant, C. C. (1990). Native ethics and rules of behaviour. Canadian Journal of Psychiatry, 35(6), 534-539.

Connors, E. A., \& Oates, M. L. B., Jr. (1997). The emergence of child sexual abuse treatment models within First Nations communities. In D. A. Wolfe, R. J. McMahon, \& R. D. Peters (Eds.), Child abuse: New directions in prevention and treatment across the lifespan (pp. 223-247). Thousand Oaks, CA: Sage.

Dapice, A. N. (2006). The medicine wheel. Journal of Transcultural Nursing, 17(3), 251-260.

Darnell, R. (1981). Taciturnity in Native American etiquette: A Cree case. Culture, 1(2), 55-60.

Darnell, R. (1988). The implications of Cree interactional etiquette. In R. Darnell \& M. K. Foster (Eds.), Native North American interaction patterns (pp. 69-77). Ottawa: National Museums of Canada.

Devereux, G. (1951). Three technical problems in the psychotherapy of Plains Indian patients. American Journal of Psychotherapy, $V(3), 411-423$.
Duran, E. (2006). Healing the soul wound: Counseling with American Indians and other Native peoples. New York, NY: Teacher's College Press.

Fisher, C. B. (2007). Paper three: Relational ethics and research with vulnerable populations. Online Ethics Center for Engineering. Downloaded on August 7, 2007 from www.onlineethics.dnsalias. com/CMS/research/resref/nbacindex/mindex/mpaper3.aspx.

Fisher, P. A., \& Ball, T. J. (2003). Tribal participatory research: Mechanisms of a collaborative model. American Journal of Community Psychology, 32(3), 207-216.

French, L. A. (2004). Alcohol and other drug addictions among Native Americans: The movement toward tribal-centric treatment programs. Alcoholism Treatment Quarterly, 22(1), 81-91.

Furedi, F. (2004). Therapy culture: Cultivating vulnerability in an age of uncertainty. London: Routledge.

Gone, J. P. (2004). Mental health services for Native Americans in the 21st century United States. Professional Psychology: Research and Practice, 35(1), 10-18.

Gone, J. P. (2007). "We never was happy living like a Whiteman": Mental health disparities and the postcolonial predicament in American Indian communities. American Journal of Community Psychology, 40(3-4), 290-300.

Gone, J. P. (2008). The Pisimweyapiy counselling centre: Paving the red road to wellness in northern Manitoba. In J. B. Waldram (Ed.), Aboriginal healing in Canada: Studies in therapeutic meaning and practice (pp. 131-203). Ottawa, ON: Aboriginal Healing Foundation.

Gone, J. P. (2009a). A community-based treatment for Native American historical trauma: Prospects for evidence-based practice. Journal of Consulting \& Clinical Psychology, 77(4), $751-762$.

Gone, J. P. (2009b, April). Research reservations: Bridging academy and community in tribal health research. Invited keynote address for Intersecting Interests: Tribal Knowledge and Research Communities Conference, Center for Native Health Partnerships. Montana State University, Chico Hot Springs, MT.

Gone, J. P. (2010). Psychotherapy and traditional healing for American Indians: Exploring the prospects for therapeutic integration. The Counseling Psychologist, 38(2), 166-235.

Gone, J. P., \& Kirmayer, L. J. (2010). On the wisdom of considering culture and context in psychopathology. In T. Millon, R. F. Krueger, \& E. Simonsen (Eds.), Contemporary directions in psychopathology: Scientific foundations of the DSM-V and ICD11 (pp. 72-96). New York: Guilford Press.

Hsieh, H. F., \& Shannon, S. E. (2005). Three approaches to qualitative content analysis. Qualitative Health Research, 15(9), 1277-1288.

Jilek, W. (1971). From crazy witch doctor to auxiliary psychotherapist: The changing image of the medicine man. Psychiatria Clinica, 4, 200-220.

Jilek, W., \& Todd, N. (1974). Witch doctors succeed where doctors fail: Psychotherapy among Coast Salish Indians. Canadian Psychiatric Association Journal, 19(4), 351-356.

Kahn, M. W., Lejero, L., Anton, M., Francisco, D., \& Manual, J. (1988). An indigenous community mental health service on the Tohono O'odham (Papago) Indian reservation: Seventeen years later. American Journal of Community Psychology, 16(3), 369-379.

Kahn, M. W., Williams, C., Galvez, E., Lejero, L., Conrad, R., \& Goldstein, G. (1975). The Papago psychology service: A community mental health program on an American Indian reservation. American Journal of Community Psychology, 3(2), 81-97.

Kirmayer, L. J., Brass, G. M., \& Tait, C. L. (2000). The mental health of Aboriginal peoples: Transformations of identity and community. Canadian Journal of Psychiatry, 45, 607-616. 
LaFromboise, T. D., Trimble, J. E., \& Mohatt, G. V. (1990). Counseling intervention and American Indian tradition: An integrative approach. The Counseling Psychologist, 18(4), 628-654.

Leon, R. L. (1968). Some implications for a preventive program for American Indians. American Journal of Psychiatry, 125(2), 232-236.

Manson, S. M., Garroutte, E. M., Goins, R. T., \& Henderson, P. N. (2004). Access, relevance, and control in the research process: Lessons from Indian country. Journal of Aging \& Health, 16 (5 Suppl), 58S-77S.

McFarland, B. H., Gabriel, R. M., Bigelow, D. A., \& Walker, R. D. (2006). Organization and financing of alcohol and substance abuse programs for American Indians and Alaska Natives. American Journal of Public Health, 96(8), 1469-1477.

McShane, D. (1987). Mental health and North American Indian/ Native communities: Cultural transactions, education, and regulation. American Journal of Community Psychology, 15(1), 95-116.

Mohatt, G. V., Hazel, K. L., Allen, J., Stachelrodt, M., Hensel, C., \& Fath, R. (2004). Unheard Alaska: Culturally anchored participatory action research on sobriety with Alaska Natives. American Journal of Community Psychology, 33(3/4), 263-273.

Moskowitz, E. S. (2001). In therapy we trust: America's obsession with self-fulfillment. Baltimore, MD: Johns Hopkins University.

Polsky, A. J. (1991). The rise of the therapeutic state. Princeton, NJ: Princeton University.

Preston, R. J. (1975). Reticence and self-expression: A study of style in social relationships. Papers of the Algonquian Conference, 7 , 450-494.

Prussing, E. (2008). Sobriety and its cultural politics: An ethnographer's perspective on "culturally appropriate" addiction services in Native North America. Ethos, 36(3), 354-375.
Royal Commission on Aboriginal Peoples. (1996). Report of the royal commission on aboriginal peoples. Ottawa, ON: Royal Commission on Aboriginal Peoples.

Shweder, R. A. (1994). Fundamentalism for highbrows. Academe, 80(6), 13-21.

Sue, S., Allen, D. B., \& Conaway, L. (1978). The responsiveness and equality of mental health care to Chicanos and Native Americans. American Journal of Community Psychology, 6(2), 137-146.

Torrey, E. F. (1970). Mental health services for American Indians and Eskimos. Community Mental Health Journal, 6(6), 455-463.

U. S. Department of Health and Human Services. (2001). Mental health: Culture, race, and ethnicity-A supplement to Mental health: A report of the Surgeon General. Rockville, MD: U. S. Department of Health and Human Services.

Waldram, J. B. (Ed.). (2008). Aboriginal healing in Canada: Studies in therapeutic meaning and practice. Ottawa, Ontario: Aboriginal Healing Foundation.

Waldram, J. B., Innes, R., Kaweski, M., \& Redman, C. (2008). Building a Nation: Healing in an urban context. In J. B. Waldram (Ed.), Aboriginal healing in Canada: Studies in therapeutic meaning and practice (pp. 205-268). Ottawa, ON: Aboriginal Healing Foundation.

Ward, S. C. (2002). Modernizing the mind: Psychological knowledge and the remaking of society. Westport, CT: Praeger.

Warner, J. C. (2003). Group therapy with Native Americans: Understanding essential differences. Group, 27(4), 191-202.

Weibel-Orlando, J. (1989). Hooked on healing: Anthropologists, alcohol, and intervention. Human Organization, 48(2), 148-155.

Wilcox, D. M. (1998). Alcoholic thinking: Language, culture, and belief in Alcoholic's anonymous. Westport, CT: Praeger.

Young, D., Ingram, G., \& Swartz, L. (1989). Cry of the eagle: Encounters with a Cree healer. Toronto: University of Toronto Press. 